ORNL/TM-2018/1032

CRADA/NFE-16-03672

\title{
Explore the Techno-Economic Viability of Using Large-Scale Additive Manufacturing for High-Performance Windows
}

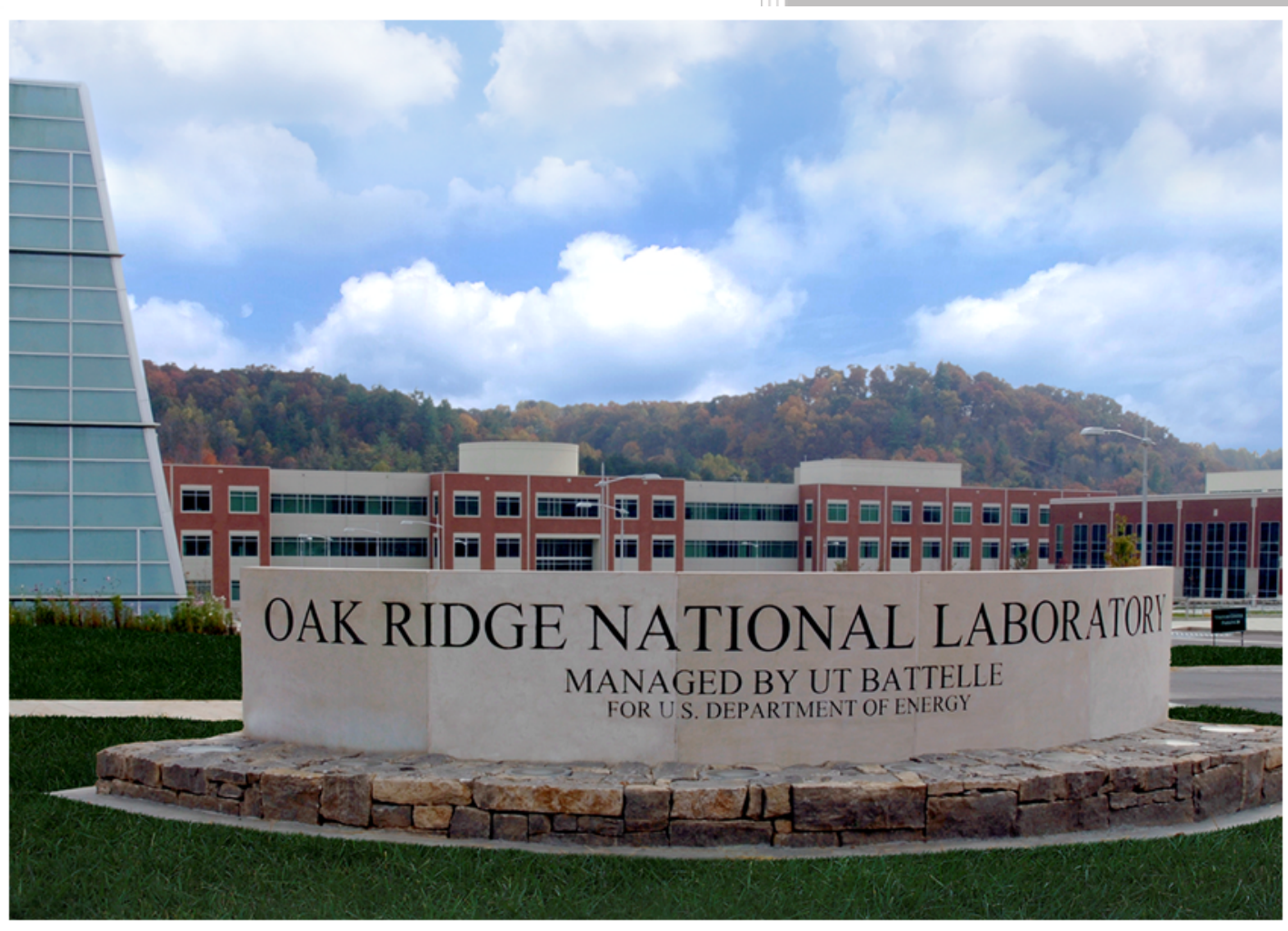

Lonnie Love

September 27, 2018

CRADA FINAL REPORT

NFE-16-06372

Approved for Public Release.

Distribution is Unlimited.

OAK RIDGE NATIONAL LABORATORY 


\section{DOCUMENT AVAILABILITY}

Reports produced after January 1, 1996, are generally available free via US Department of Energy (DOE) SciTech Connect.

Website http://www.osti.gov/scitech/

Reports produced before January 1, 1996, may be purchased by members of the public from the following source:

National Technical Information Service
5285 Port Royal Road
Springfield, VA 22161
Telephone 703-605-6000 (1-800-553-6847)
TDD 703-487-4639
Fax 703-605-6900
E-mail info@ntis.gov
Website http://www.ntis.gov/help/ordermethods.aspx

Reports are available to DOE employees, DOE contractors, Energy Technology Data Exchange representatives, and International Nuclear Information System representatives from the following source:

Office of Scientific and Technical Information

PO Box 62

Oak Ridge, TN 37831

Telephone 865-576-8401

Fax 865-576-5728

E-mail reports@osti.gov

Website http://www.osti.gov/contact.html

This report was prepared as an account of work sponsored by an agency of the United States Government. Neither the United States Government nor any agency thereof, nor any of their employees, makes any warranty, express or implied, or assumes any legal liability or responsibility for the accuracy, completeness, or usefulness of any information, apparatus, product, or process disclosed, or represents that its use would not infringe privately owned rights. Reference herein to any specific commercial product, process, or service by trade name, trademark, manufacturer, or otherwise, does not necessarily constitute or imply its endorsement, recommendation, or favoring by the United States Government or any agency thereof. The views and opinions of authors expressed herein do not necessarily state or reflect those of the United States Government or any agency thereof. 
ORNL/TM-2018/1032

CRADA/NFE-16-06372

Energy and Transportation Sciences Division

Advanced Manufacturing Office

\title{
Explore the Techno-Economic Viability of Using Large-Scale Additive Manufacturing (AM) For High-Performance Windows
}

\author{
Authors \\ Lonnie Love \\ Alex Roschli \\ Brian Post \\ Katherine Gaul
}

Date Published:

September 27, 2018

Prepared by

OAK RIDGE NATIONAL LABORATORY

Oak Ridge, Tennessee 37831-6283

managed by

UT-BATTELLE, LLC

for the

US DEPARTMENT OF ENERGY

under contract DE-AC05-00OR22725

Approved For Public Release 


\section{CONTENTS}

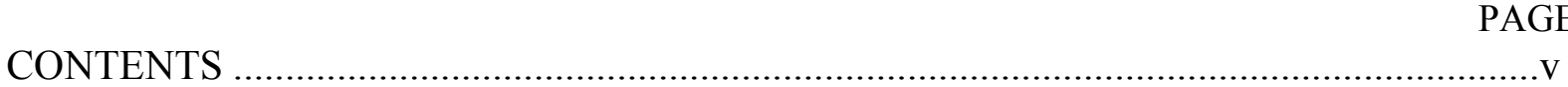

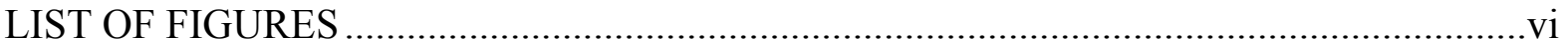

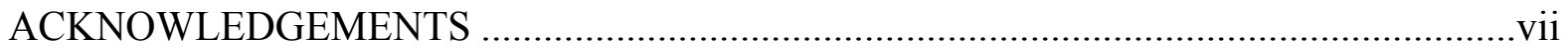

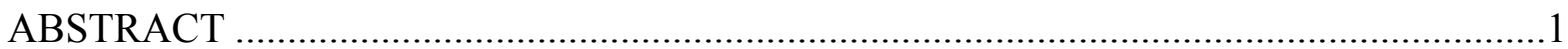

1. EXPLORE THE TECHNO-ECONOMIC VIABILITY OF USING LARGE-SCALE ADDITIVE MANUFACTURING (AM) FOR HIGH-PERFORMANCE WINDOWS...........1

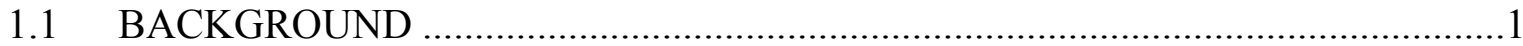

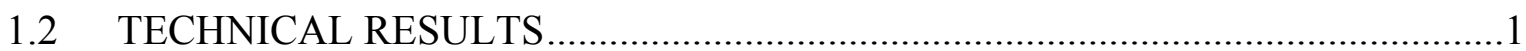

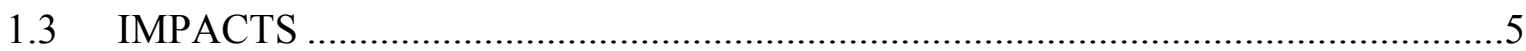

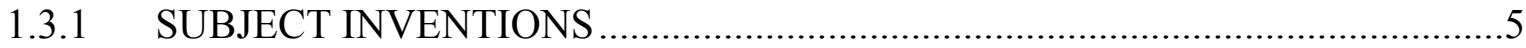

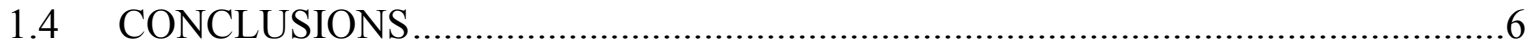

2. ALCOA, KAWNEER, AND ALCOA TECHNICAL CENTER BACKGROUND...........8 


\section{LIST OF FIGURES}

Fig. 1. Window frames shown during the additive manufacturing process. .........................2

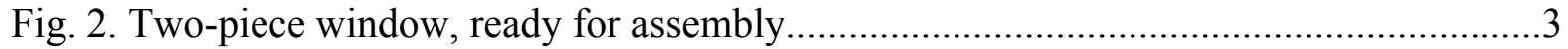

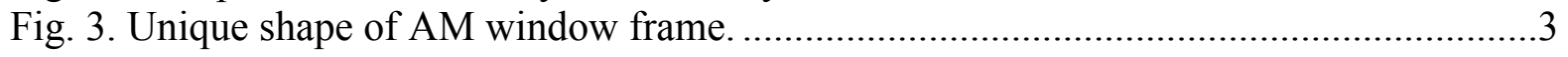

Fig. 4. Oval shaped AM window frame. ................................................................

Fig. 5. AM window frame with glass inserted.........................................................

Fig. 6. Three AM window frames inserted into constructed frame....................................5

Fig. 7. A single AM window frame inserted into constructed frame. ..................................5

Fig. 8. Comparison of the three window frame printing methods.....................................6 


\section{ACKNOWLEDGEMENTS}

This CRADA NFE-16-06372 was conducted as a Technical Collaboration project within the Oak Ridge National Laboratory (ORNL) Manufacturing Demonstration Facility (MDF) sponsored by the US Department of Energy Advanced Manufacturing Office (CPS Agreement Number 24761).

Opportunities for MDF technical collaborations are listed in the announcement "Manufacturing Demonstration Facility Technology Collaborations for US Manufacturers in Advanced

Manufacturing and Materials Technologies" posted at http:/web.ornl.gov/sci/manufacturing/docs/FBO-ORNL-MDF-2013-2.pdf. The goal of technical collaborations is to engage industry partners to participate in short-term, collaborative projects within the Manufacturing Demonstration Facility (MDF) to assess applicability and of new energy efficient manufacturing technologies. Research sponsored by the U.S. Department of Energy, Office of Energy Efficiency and Renewable Energy, Advanced Manufacturing Office, under contract DE-AC0500OR22725 with UT-Battelle, LLC. 


\begin{abstract}
Use of 3D printing, or additive manufacturing (AM) technology, in window design and construction is an under-explored area of research. Given the rapid advancements in AM technology and the potential for AM to address significant challenges associated with window design and manufacturing, there was a need to explore the feasibility of using AM technology.

Alcoa's Kawneer (Alcoa Building and Construction Systems) partnered with Oak Ridge National Laboratory's (ORNL) Manufacturing Demonstration Facility (MDF) to explore the technical and commercial viability of large-scale 3D printing technologies with Kawneer's AM window design. The project combined Alcoa/Kawneer's design and expertise with ORNL's equipment capability to create and study the world's first 3D printed window using Big Area Additive Manufacturing (BAAM) technology. The results show that AM is useful for creating custom window shapes and sizes. With AM, more efficient windows can be made by sealing the glass pane into the printed frame during the printing process. In addition to energy savings, the use of AM reduces the manual labor required to produce custom windows.
\end{abstract}

\title{
1. EXPLORE THE TECHNO-ECONOMIC VIABILITY OF USING LARGE-SCALE ADDITIVE MANUFACTURING (AM) FOR HIGH-PERFORMANCE WINDOWS
}

This phase one technical collaboration project (MDF-TC-2016-102) began September 15, 2016 and was completed on September 28, 2018. Alcoa is a large business, and this project found that additive manufacturing is a very useful tool for creating custom energy efficient windows.

\subsection{BACKGROUND}

Current window manufacturing practices are highly labor-intensive (more than one-third of product cost is from labor), and the scope for automation is limited due to high customization requirements (e.g. sizes, configurations). Additive manufacturing (AM) presents an interesting opportunity to significantly reduce labor, material cost, production time, number of parts, add customization benefits, enable faster product design and development cycle, and enhance product performance.

Oak Ridge National Laboratory's (ORNL) Manufacturing Demonstration Facility (MDF) was the ideal partnership for the research venture because the MDF has the engineering expertise and equipment to thoroughly research the applicability of large area 3D printing for window manufacturing.

ORNL proposed the use of Big Area Additive Manufacturing (BAAM) to address the issues associated with high cost and extensive manual labor. Using the BAAM process, several designs of custom windows could be fabricated during a single print, each taking minutes to complete. The complex, two-piece window designs could be drawn out precisely in computer aided design (CAD), and then transferred to the BAAM printer where complexity of the object to be printed is irrelevant. Traditional manufacturing requires a custom mold or form be made for each specific window design, but BAAM does not require molds. The window frames could be modeled and then printed immediately.

Metrics for success were established in the following ways: Multiple custom designs would be fabricated during a single print on the BAAM printer. The designs would be unique and energy efficient. The print would be completed in a timely manner. 


\subsection{TECHNICAL RESULTS}

Overall, this phase one technical collaboration was a success. Kawneer provided ORNL with product specifications and designed CAD models appropriate for AM. ORNL provided material guidance and selection, cost estimates for the 3D printing process, and used BAAM technology to manufacture several window prototypes.

The window prototypes were manufactured using carbon fiber reinforced acrylonitrile butadiene styrene (CF-ABS) polymer. Each window consisted of two pieces, which took approximately 20 minutes per set to 3D print. The windows weighed 22lbs each. Fig. 1 shows three window frame sets as they were being fabricated in the BAAM machine. The build volume of the additive manufacturing system determines how many sets you can print in a single build. As shown in Fig. 1, the BAAM system can print up to five sets - one set per build sheet. Fig. 2 shows one complete frame prototype, ready to be assembled.

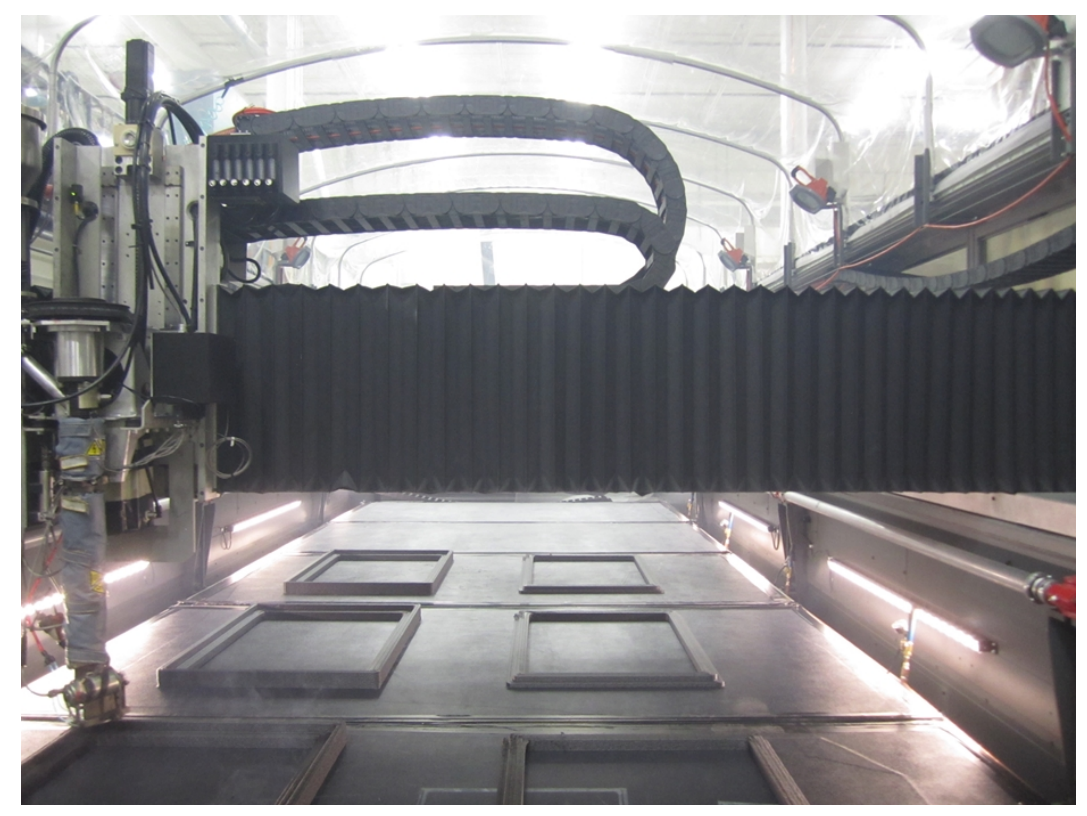

Fig. 1. Window frames shown during the additive manufacturing process.

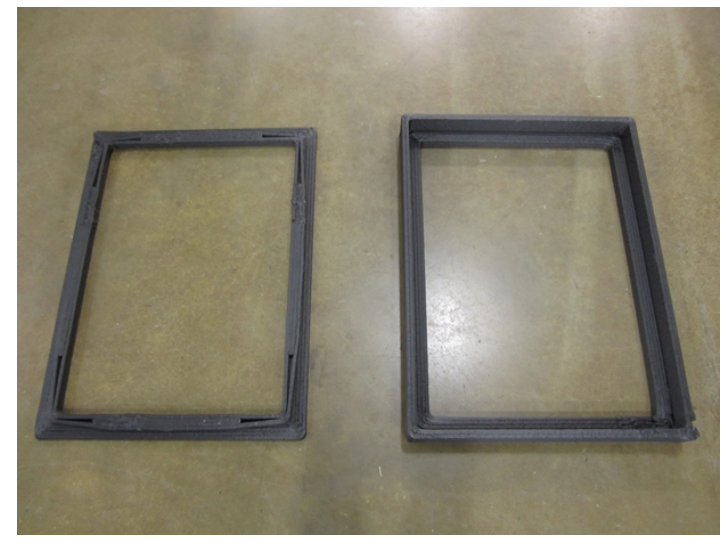

Fig. 2. Two-piece window, ready for assembly.

Design features included curved sides and void areas that assisted with frame malleability and 
overall fit by increasing friction to hold the two pieces together.

Researchers at the MDF explored different shapes of window frames to validate the customization that AM provides to the manufacturing process. The various shapes of window prototypes are shown in Fig. 3 and Fig. 4.

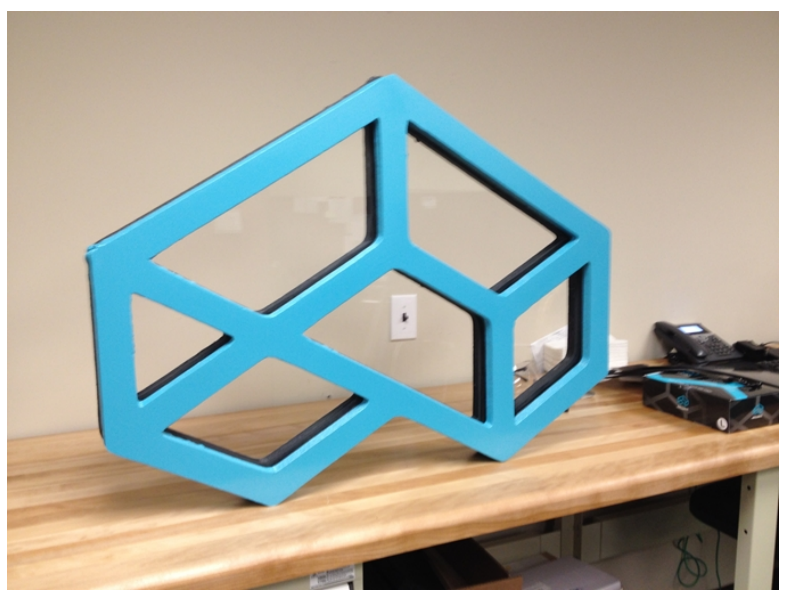

Fig. 3. Unique shape of AM window frame.

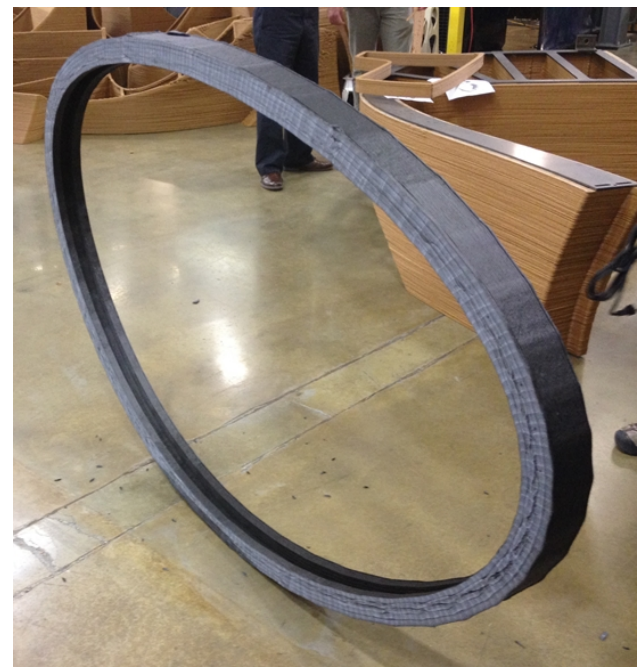

Fig. 4. Oval shaped AM window frame.

Later designs of the windows involved inserting glass into the part during printing. For testing, the insertion was done manually by a human while the print was paused. Inserting the glass into the molten polymer during printing meant having an airtight seal around the window. With a tight seal, no caulk is needed around the glass and no assembly of the frame is needed. At the completion of the printing, as shown in Fig. 5, the window can be removed from the printer and is ready for use. 


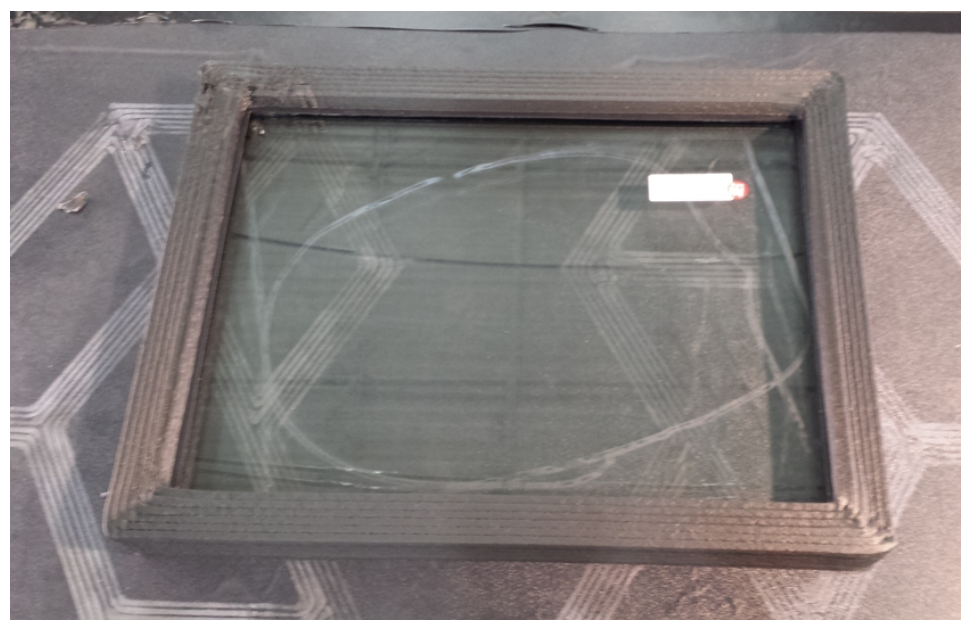

Fig. 5. AM window frame with glass inserted.

After the window frames were printed at the MDF, they were shipped to Kawneer. Kawneer then constructed sample walls into which the test windows were installed (Figs. 6 and 7). Validation of window performance was then completed. Kawneer found the prototypes to have good structural properties, but felt further work was necessary to improve the aesthetic and versatility of the asprinted frame.

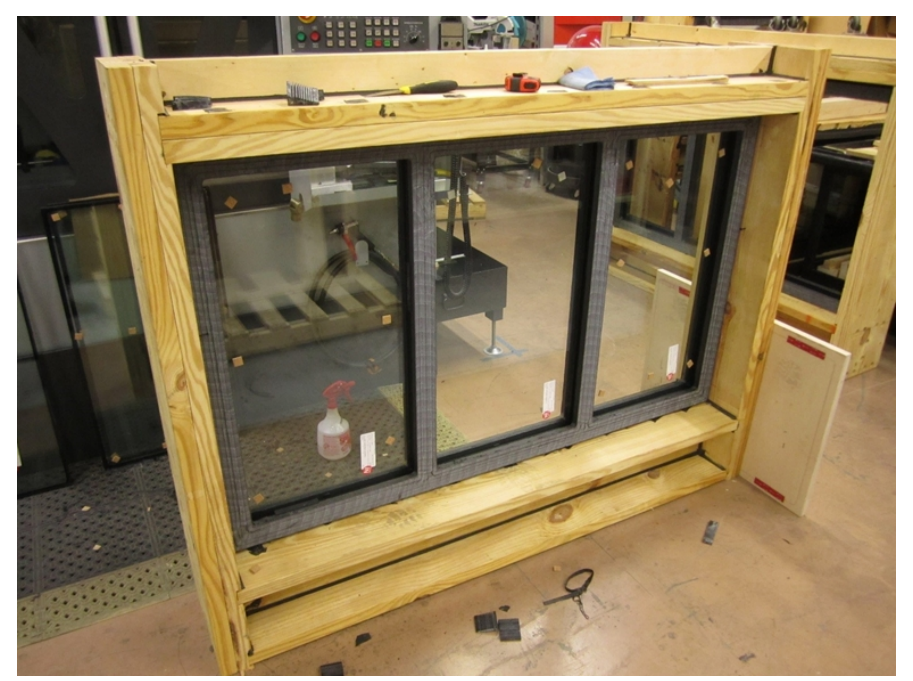

Fig. 6. Three AM window frames inserted into constructed frame. 


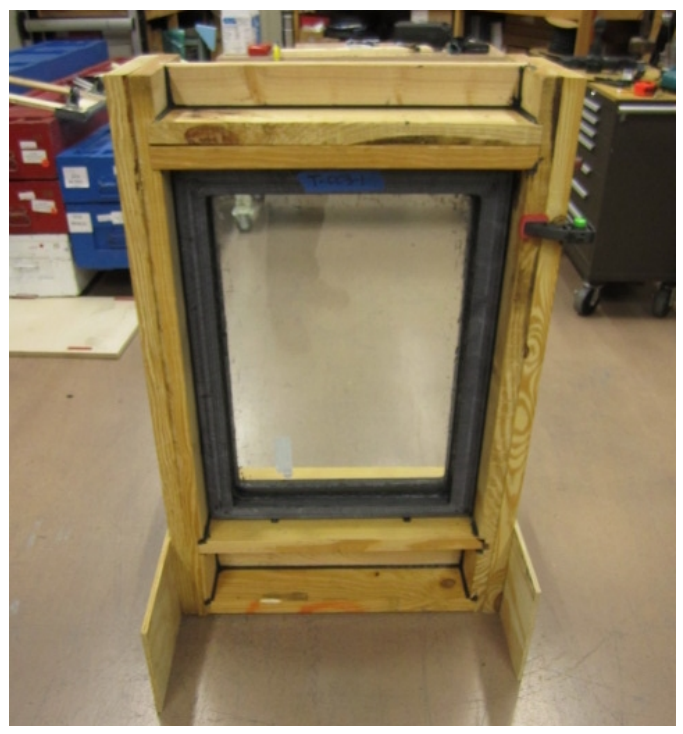

Fig. 7. A single AM window frame inserted into constructed frame.

With the current means of slicing (preparing the computer design file for printing), there are two methods of producing a frame. The first method involves printing the outer perimeter of the frame and continually offsetting inwards until the desired bead width is achieved. The obstacle here is that the desired width measurement of the finished window must be a multiple of the bead width. For example, a 1.5 " thick window frame cannot be made using a 0.34 " bead width. The other problem with this method is that there are starts and stops for each bead, making an imperfect seam that effects the ability to inset a perfectly square sheet of glass.

The second method of producing a frame involves printing the outer and inner perimeters, then filling between them with a raster. This allows for more flexible dimensions, such as a 1.5" thick window frame. However, the raster pattern might not create a perfect air and water tight seal, which would decrease the window's efficiency.

As a result, Kawneer proposed a third method that was an adaption of the first method. Instead of offsetting the outer perimeter inwards, the outer perimeter was spiraled inward. This made for just one start and stop per layer, which increased the accuracy of the printed right angles. The drawback is that this approach has geometric limitations. A simple shape, such as a rectangular window frame, is the ideal application of spiralized printing. However, if Kawneer were to pursue more complex geometries, the spiralizing technique can become more difficult. The three methods can be seen in Figure 8. 

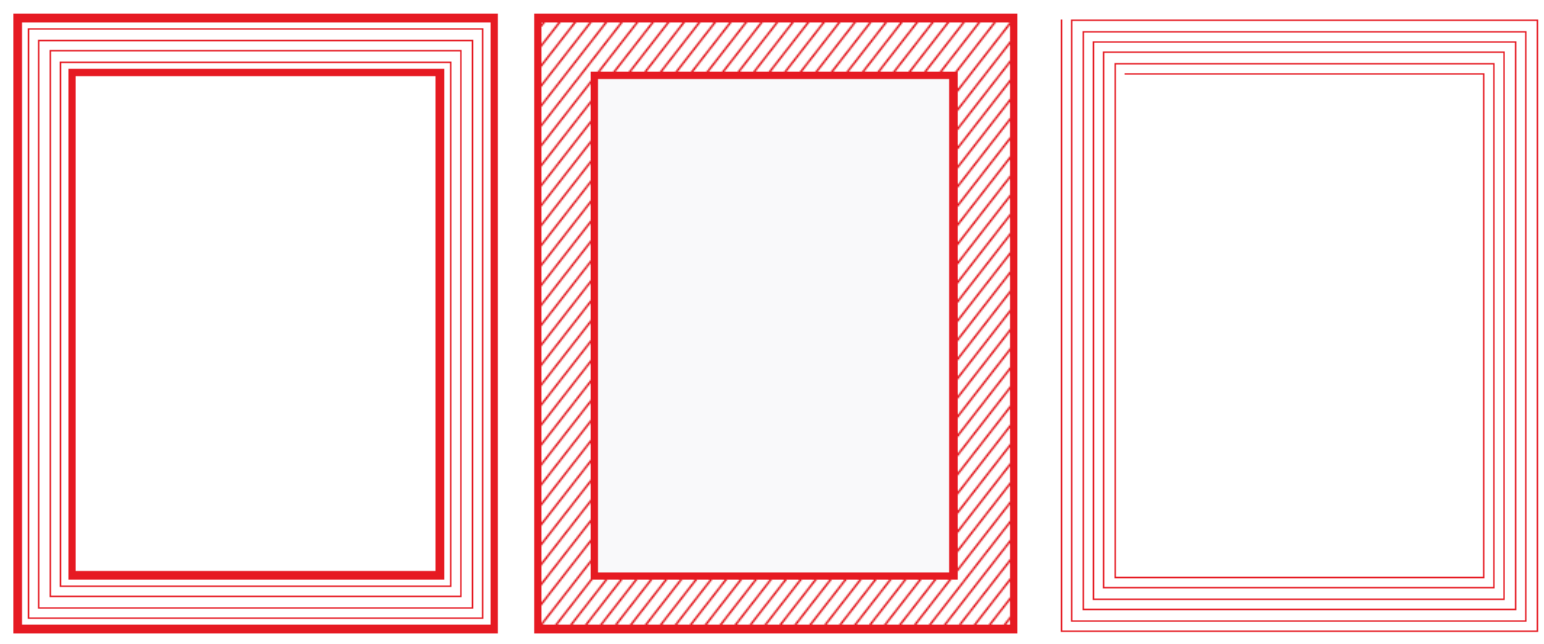

Fig. 8. Comparison of the three window frame printing methods.

\section{$1.3 \quad$ IMPACTS}

This project had several impacts - it was a novel project; it researched a way to find cost-savings in an industry that is required for almost every building; it resulted in the creation of a tool that can be used to evaluate the cost of AM windows; and it provided an avenue for an industry leader to save energy in manufacturing their product.

Novelty: At the time of this project, no one had attempted to design and develop windows for production using AM. This was the first project that focused on understanding the design and production efficiencies (or limitations) of AM over current methods.

Cost-Savings: AM provided design, production, and lead-time efficiencies that could lead to lower product cost if deployed long term.

Tool to Evaluate Window Cost Using AM: A tool was developed in this project that forecasts the costs of windows fabricated using AM, which can then be used to develop a model to forecast the production window cost.

Energy-Savings: Design and production using AM reduces the process energy used, and the windows themselves were found to be more energy efficient because the glass can be inserted during the printing process creating a potentially perfect, airtight seal. However, Kawneer had concerns about the defects created by starts and stops and geometric limitations of the spiralized approach.

\subsubsection{SUBJECT INVENTIONS}

There were no subject inventions as a result of this project.

\subsection{CONCLUSIONS}

Overall, the project was a success. Alcoa/Kawneer designed and provided several window CAD models. The MDF fabricated several window frames from the models including frames where the glass was inserted during printing. ORNL also developed a new method of creating toolpaths for printing the frame prototypes. Kawneer took delivery of the frames and did structural testing by inserting them into a pseudo building. The structural testing proved to be viable in both material strength and energy efficient of the window frames. 


\section{ALCOA, KAWNEER, AND ALCOA TECHNICAL CENTER BACKGROUND}

Alcoa was founded in 1888 by Charles Martin Hall and his patent for a cost-effective process for producing aluminum. Today, Alcoa is the world's leading integrated aluminum company, providing jobs to 61,000 employees in more than 200 locations across 31 countries. Since inventing the modernday aluminum industry more than 120 years ago, Alcoa innovation has been behind major milestones in the aerospace, automotive, packaging, building and construction, commercial transportation, defense, consumer electronics, and industrial markets.

Kawneer is a manufacturer of architectural aluminum systems and products for the commercial construction industry. Headquartered in Norcross, Georgia, Kawneer has offices in 13 countries in North America, Europe, North Africa, and Asia. Kawneer is part of Alcoa's global Building and Construction Systems (BCS) business unit. Kawneer's architectural aluminum product range includes windows and doors, framing systems, curtain wall systems, railings, shutters, and conservatories. Kawneer products are used on high- mid- and low-rise non-residential buildings such as stadiums and sports facilities, office buildings, schools, colleges and universities, retail construction, and healthcare facilities.

The Alcoa Technical Center (ATC) is Alcoa's largest research, development, and applied engineering laboratory. This facility is the world's largest light metals R\&D center with a full range of lab capabilities, from bench-scale to full production-scale equipment. There are approximately 270 labs on site in the seven main buildings that comprise the majority of the complex. The facility has a workforce of approximately 685, with more than 100 holding doctorate and 200 holding master's degrees. Internal R\&D at the Alcoa Technical Center includes: alloy \& temper development; ingot casting development; metal processing development; product design and development; product manufacturing development (joining, forming, machining); development of engineered surfaces and finishes; development of environmental and sustainability technologies; and surface science. 